\title{
A Comparison of the Psychological Characteristics of Male and Female Able-bodied and Wheelchair Athletes
}

\author{
Michael Horvat, Ed.D., ${ }^{1}$ Ron French, Ed.D. ${ }^{2}$ and Keith Henschen, \\ P.E.D. ${ }^{3}$ \\ ${ }^{1}$ Division of HPERD, University of Georgia, Athens, U.S.A., ${ }^{2}$ Department of \\ Physical Education, Texas Woman's University, Denton, Texas, U.S.A., ${ }^{3}$ College \\ of Health, University of Utah, Salt Lake City, Utah, U.S.A.
}

\section{Summary}

The purpose of this study was to compare selected psychological characteristics between male and female able-bodied and wheelchair athletes. All subjects completed the Profile of Mood States (POMS). Morgan (1980) has reported that based on the POMS elite able-bodied male and female athletes possess superior mental and emotional health compared to the general population. Based on this investigation, this result can now be extended to male and female wheelchair athletes.

Key words: Psychological characteristics of wheelchair athletes; Comparison with able-bodied athletes.

\section{Introduction}

Organised sports competition for male and female wheelchair individuals is in its embryonic stages of development when compared to sports for the able-bodied. The first games were held in 1948 at Stoke Mandeville, England and attracted only 16 competitors. The number of competitors, as well as the number of events has continually grown since this time. In 1984, there were over 3000 athletes representing 50 countries who participated in the United States at the Olympics for the Physically Disabled.

Steadward (1980) stated that unfortunately the rapid growth in the number of athletes, as well as sports events, has not been accompanied by a similar development in coaching and training methods for this population. As a result the most recent information available on training with able-bodied athletes has not been applied to this population. One specific area of training for wheelchair athletes which has been neglected is psychological preparation for competition (Daniel \& Gorman, 1983). The personality of an athlete directly impacts on his/her performance. For instance, some athletes find it hard 'to get motivated', while others have problems because they get over excited, or 'psych themselves out'. All these behaviours negatively impact optimum performance (Cratty, 1983).

Coaches from some east European countries have recognised this for at least 
two decades and have utilised the results from psychological assessments to design and implement psychological training concurrently with their traditional physical training programmes (Hanin, 1980). The main purpose of this psychological training has been to increase the probability that highly skilled athletes will consistently perform to the best of their abilities (Cratty, 1983). Due to the success of such a comprehensive training programme, similar offerings are currently being formulated and adapted for able-bodied athletes in many Western countries (Henschen, Edwards, Gordin, \& Ravizza, 1984; Williams \& Parkin, 1980).

Much research has been conducted on the psychological profiles of elite level able-bodied athletes in many sports. A common profile has been demonstrated among various world class athletes which is referred to as an "Iceberg Profile" (Morgan, 1980). This profile involves scoring below average on the tension, depression, anger, fatigue, and confusion subscales on the Profile of Mood States instrument while scoring very high on the vigour subscale. To date only a few studies have been reported related to the emotional states of handicapped athletes, and virtually no studies related to female handicapped athletes.

Monnazzi (1982) has reported, using the Middlesex Hospital Questionnaire to collect data, that male and female athletic paraplegics have similar personality characteristics to athletic able-bodied individuals in the areas of anxiety, phobia, obsession, somatisation and depression; similar personality characteristics to non-athletic able-bodied individuals except in the area of anxiety; and are only similar to the non-athletic paraplegic individuals in the area of hysteria. It has been suggested that sport-therapy could attenuate the pyschoneurotic personality traits in the rehabilitated paraplegic concerning anxiety, phobia, obsession, somatisation, and depression without any influence on hysteria. Henschen, Horvat, and French (1984), using the State-Trait Anxiety Inventory and the Profile of Mood States instruments, also suggested that the personality characteristics of male wheelchair athletes are generally similar to able-bodied male athletes. In the area of anger, the wheelbound athletes did display a slightly higher level of anger than would be expected for able-bodied athletes, but it was in the normal range. In the Monnazzi (1982) investigation only one of the 22 paraplegic athletes and three of the 16 paraplegic non-athletes were female; while in the Henschen, Horvat, and French (1984) study, all the subjects were males.

Since pyschological programmes have been so successful with able-bodied male and female athletes, then it is reasonable to assume these same programmes would be equally effective with handicapped athletes; if able-bodied and handicapped athletes are similar psychologically. Therefore, the purpose of this investigation was to compare selected psychological characteristics between male and female able-bodied and wheelchair athletes.

\section{Methods}

\section{Subjects}

The male subjects for this investigation were 33 wheelchair athletes who competed in a Regional Qualifying Track Meeting for national wheelchair competition and 98 able-bodied elite level athletes from NCAA championship gymnastics teams, Olympic oarsmen, wrestlers, and marathoners. The male wheelchair athletes were between 18 and 35 years of age and were part of a study 
previously reported by Henschen, Horvat, and French (1984). The male ablebodied subjects were those athletes used in studies reported by Morgan and Johnson (1977; 1978), Morgan and Pollock (1977), and Henschen, Edwards, Gordin and Ravizza (1984).

The female subjects for this study were 62 wheelchair athletes between 19 and 37 years of age who were members of one of 10 teams to qualify to participate in the Tenth Annual Woman's National Wheelchair Basketball Tournament. The able-bodied female subjects were 58 gymnasts who competed in the 1982 NCAA National Woman's Gymnastics Championships (Henschen, et al., 1984).

The male and female wheelchair subjects had various lower limb impairments resulting from spinal cord injuries, poliomyelitis, or amputations. The degree of impairment included both paraplegia and tetraplegia.

\section{Evaluation instrument}

All subjects completed a psychological self-report instrument: The Profile of Mood States (POMS). The POMS is an adjective check list similar to Osgood's Semantic Differential in which the respondents attempt to describe how they have felt during the preceeding week. The purpose of the POMS is to identify the emotional states experienced by the subjects during the time period in question (McNair, Lorr, \& Droppleman, 1971). The test-retest reliability of the six subscales of the POMS (tension, depression, anger, vigor, fatigue and confusion) over a 20 day period ranges from $\cdot 65$ for vigour to $\cdot 74$ for depression. The internal consistency of the six subscales of the POMS range from $\cdot 87$ to 95 . Morgan (1980) stated that, 'of all the psychological tests my colleagues and I have experimented with, we found the Profile of Mood States (POMS) to be the most highly predictive of athletic success".

Researchers have also provided evidence for the predictive and construct validities of the POMS. Utilising short-term psychotherapy, researchers administered the POMS to 180 Veterans Administration out-patients over an 8-week period. All subjects experienced a significant level of improvement, after the treatment period, on all subscales of the POMS except vigour. It was indicated in a study of controlled outpatient drug trials that the subscales of the POMS were sensitive to short-term changes caused by medication. In addition, from studies of emotion inducing conditions, it is evident that the POMS is also sensitive to mood changes caused by a stressful event such as athletic competition (McNair, Lorr, \& Droppleman, 1971). Concurrent validity has been established from a sample of veteran administration out-patients who completed a modified version of the Hopkins Symptom Distress Scales (Parloff, Kelman, \& Frank, 1954).

\section{Results and discussion}

Illustrated in Fig. 1 is a visual comparison (reported in $T$ scores) of the personality profiles of male wheelchair athletes, Olympic oarsmen, marathoners, and Olympic wrestlers as evaluated by the POMS. All groups demonstrated the iceberg profile and had above average moods when compared to the general population. 


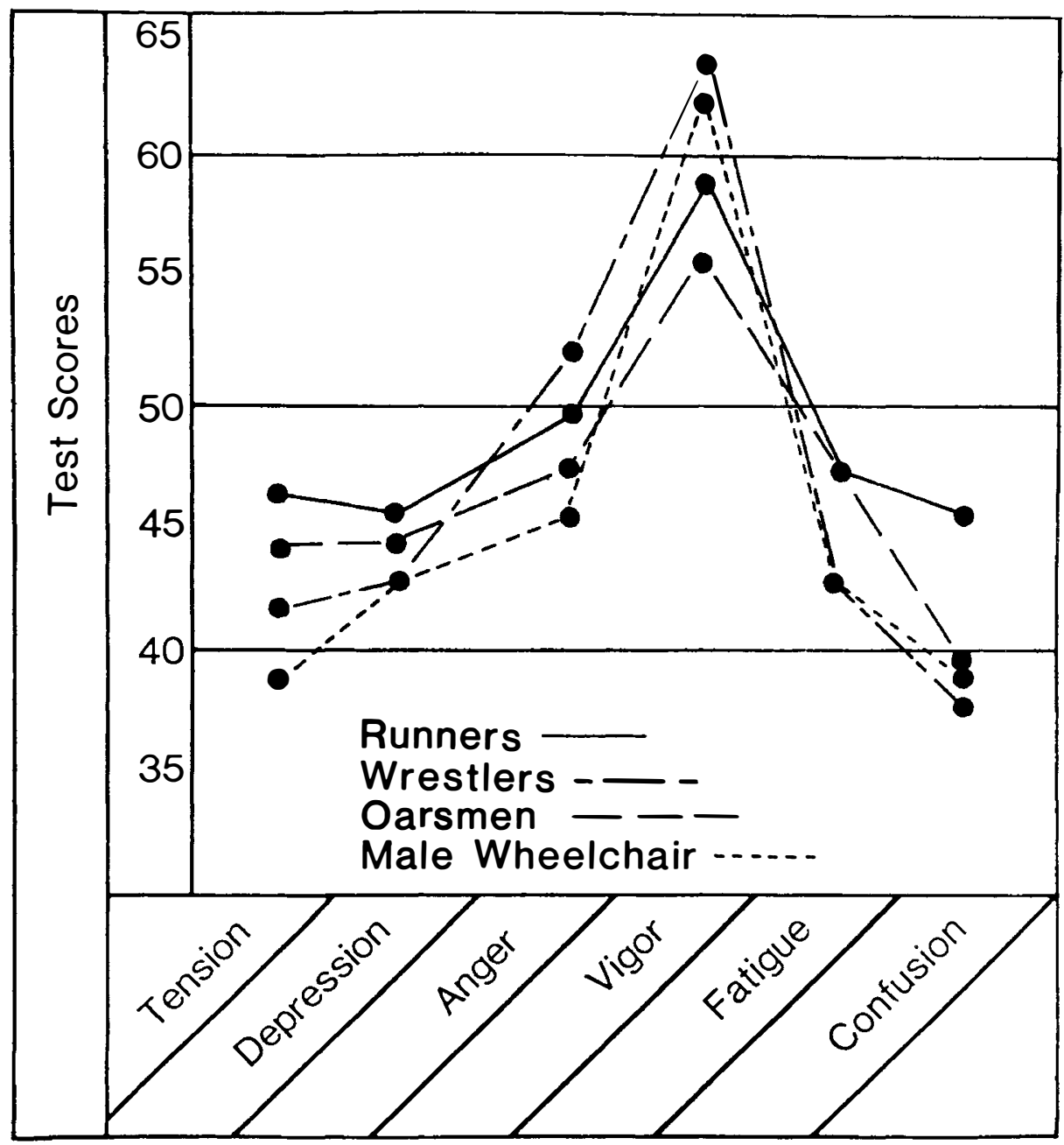

Figure 1. Visual comparison of the psychological characteristics of male wheelchair track athletes to male able-bodied runners, wrestlers and oarsmen.

Further illustrated in Fig. 2 are the POMS scores for the female wheelchair athletes and the female able-bodied elite level gymnasts. Both groups also exhibited an iceberg profile.

While the male and female wheelchair athletes both demonstrated an iceberg profile (see Fig. 3), there were differences in all their subscale scores, except in one. The results were more dramatic for the males. Based on a multivariate analysis between male and female wheelchair athletes, there was a significant group effect $(p<\cdot 019)$. Means and standard deviations of the subscale scores are presented in Table 1. Analysing the individual subscale scores using a univariate analysis, significant differences were obtained on all subscale comparisons except on the tension subscale (see Table 2 ).

These data generally support the findings of Williams (1980), who after review- 


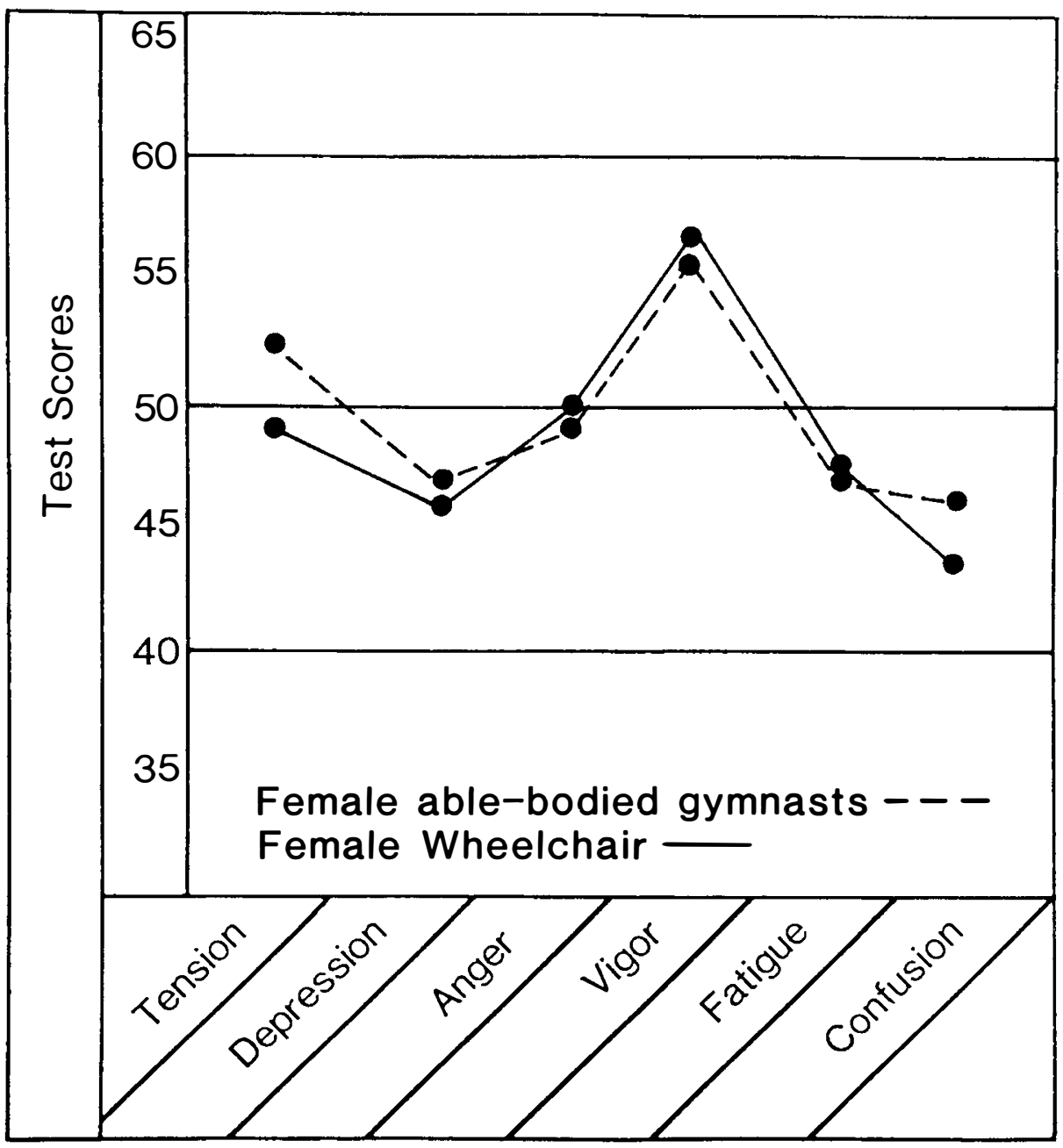

Figure 2. Visual comparison of the psychological characteristics of female wheelchair basketball players to female able-bodied gymnasts.

ing the literature of personality characteristics of successful female athletes, concluded that their personality profiles appear to resemble that of the average male and athlete male much more than the average female. The average female was characterised as passive, submissive, dependent, high emotionally and socially, and low in achievement and aggressive needs. On the other hand, the successful female athlete, similar to the average male and athlete male tend to be characterised as more assertive, dominant, self-sufficient, independent, aggressive, intelligent, reserved, higher achievement oriented, and exhibit an average to low emotionality (Cratty, 1983).

One reason why the male wheelchair athletes demonstrated a more dramatic iceberg profile than the female wheelchair athletes may have been due to the years of experience in sport where they have learned to control those personality 


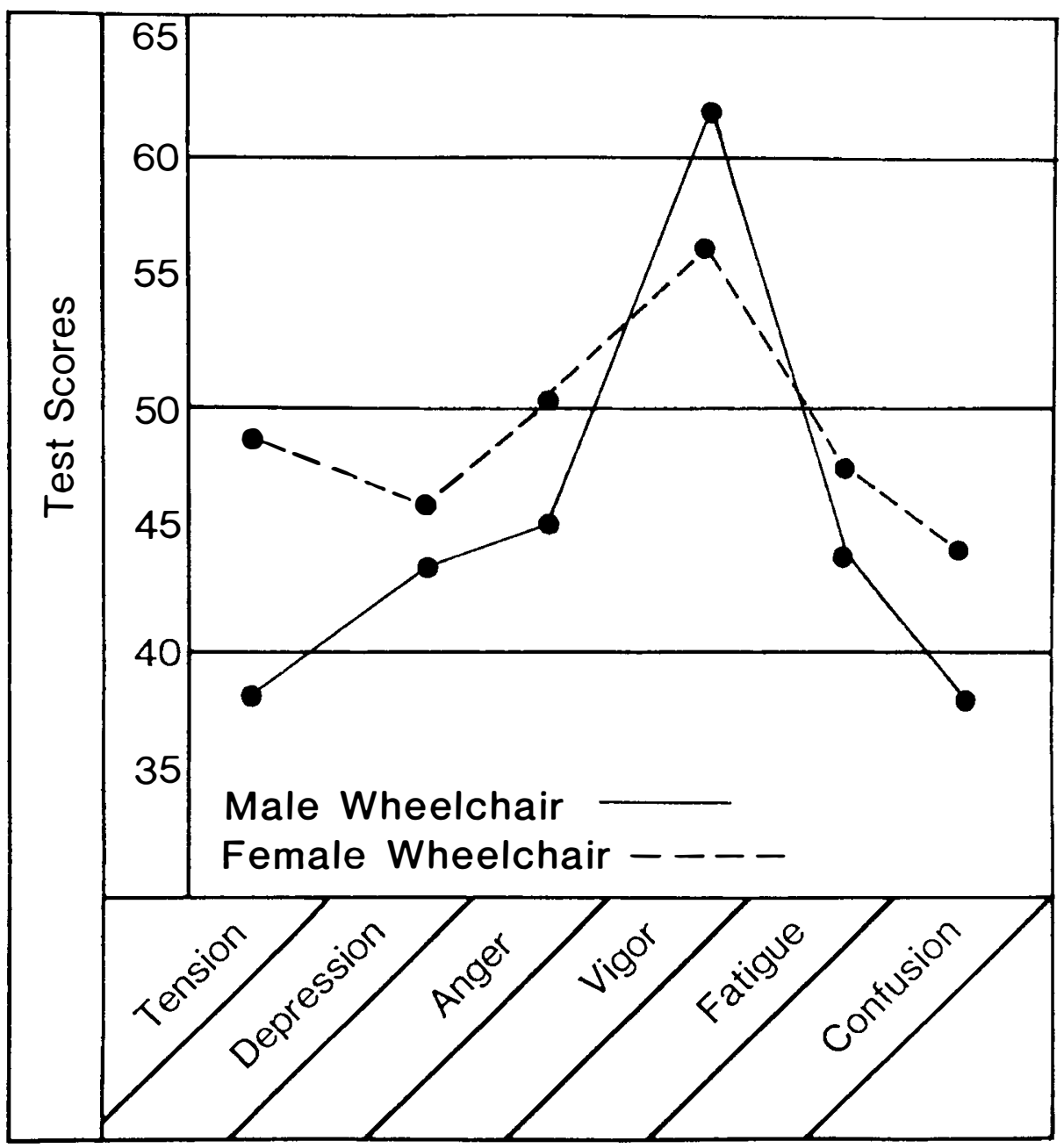

Figure 3. Visual comparison to the psychological characteristics of male wheelchair track athletes to female wheelchair basketball players.

Table 1 Means and standard deviations of the POMS subscale T scores by sex and total population

\begin{tabular}{|c|c|c|c|c|}
\hline \multirow{5}{*}{$\begin{array}{l}\text { Female }(n=62) \\
\text { Male }(n=35) \\
\text { Total population }(n=97)\end{array}$} & Tension & Depression & \multicolumn{2}{|c|}{ Anger } \\
\hline & $M \quad S D$ & $M \quad S D$ & & SD \\
\hline & $49.05 \quad 9.70$ & $45.87 \quad 7.96$ & $50 \cdot 16$ & $10 \cdot 23$ \\
\hline & $46 \cdot 77 \quad 11 \cdot 17$ & $42 \cdot 11 \quad 6 \cdot 23$ & $45 \cdot 43$ & $8 \cdot 20$ \\
\hline & $48 \cdot 23 \quad 10 \cdot 26$ & $44.55 \quad 7.51$ & $48 \cdot 45$ & $9 \cdot 64$ \\
\hline & Vigor & Fatigue & \multicolumn{2}{|c|}{ Con } \\
\hline & $M \quad S D$ & $M \quad S D$ & $\mathbf{M}$ & SD \\
\hline Female $(n=62)$ & 56.818 .73 & $47 \cdot 10 \quad 9 \cdot 72$ & 43.02 & $8 \cdot 76$ \\
\hline Male $(n=35)$ & $62 \cdot 40 \quad 7 \cdot 72$ & $42 \cdot 29 \quad 7 \cdot 72$ & 38.94 & $6 \cdot 06$ \\
\hline Total $(n=97)$ & $\begin{array}{lll}58.82 & 8.77\end{array}$ & $45 \cdot 36 \quad 9 \cdot 30$ & $41 \cdot 55$ & $8 \cdot 10$ \\
\hline
\end{tabular}

characteristics that negatively impact on athletic performance. The female wheelchair athletes could possibly be participating in a sport that was relatively new to them and women in general. Other researchers have also reported differences 
Table 2 Univariate analyses between the male and female subjects and their POMS subscale scores

\begin{tabular}{|c|c|c|c|c|c|c|}
\hline Subscale & Hypoth SS & Error SS & Hypoth MS & Error MS & $\mathbf{F}$ & Sig of $F$ \\
\hline Tension & $115 \cdot 9840$ & $9989 \cdot 0263$ & $115 \cdot 9840$ & $105 \cdot 1476$ & $1 \cdot 1031$ & $0 \cdot 296$ \\
\hline Depression & $315 \cdot 7162$ & $5098 \cdot 5106$ & $315 \cdot 7162$ & $55 \cdot 6685$ & 58827 & $0.017^{\star}$ \\
\hline Anger & $501 \cdot 0827$ & $8416 \cdot 9585$ & $501 \cdot 0827$ & $88 \cdot 5996$ & $5 \cdot 6559$ & $0.019^{\star}$ \\
\hline Vigor & $699 \cdot 9432$ & $6678 \cdot 6774$ & $699 \cdot 9432$ & $70 \cdot 2956$ & 9.9571 & $0 \cdot 002^{\star}$ \\
\hline Fatigue & $517 \cdot 8089$ & $7782 \cdot 5622$ & $517 \cdot 8089$ & $81 \cdot 9207$ & $6 \cdot 3208$ & $0 \cdot 014^{\star}$ \\
\hline Confusion & $371 \cdot 1716$ & $5930 \cdot 8696$ & $371 \cdot 1717$ & $64 \cdot 4302$ & 5.9454 & $0 \cdot 017^{\star}$ \\
\hline
\end{tabular}

${ }^{\star} \mathrm{p}<\cdot 05$.

in the personality characteristics of able-bodied male and female athletes (Kane, 1970).

\section{Conclusion}

Based on the findings in this investigation, the thesis of Morgan (1980) that elite male and female athletes possess superior mental and emotional health compared to the general population can be extended to male and female wheelchair athletes. The personality characteristics of wheelchair male track athletes and wheelchair female basketball players on the POMS very clearly exhibited the 'Iceberg Profile'.

Many wheelchair athletes not only participate in sport for the sake of sport, but also for the rehabilitation and recreational aspects of sport. It is possible that the intensity of the sport competition is diluted somewhat in the case of wheelchair athletes who may have other priorities than winning. While sports participation seems to be appropriate for developing a more positive mental outlook, one cannot assume that sports participation accounts for all the observed differences. Many wheelchair bound individuals with positive attitudes may just be inclined to participate in sports because of the accessibility for participation.

It is apparent from this study that sports participation of male and female wheelchair athletes is consistent with the psychological attributes required for intense competition. The variables so essential for optimal performance, such as low depression and anxiety levels, are apparent in able bodied and wheelchair athletes as well as vigour which is crucial for intensity. Of importance to the physician and educator are all the psychological parameters which may interfere with performance. Each athlete is unique and will respond to stress and anxiety producing situations differently. It is possible that some psychological characteristics found in the wheelchair athlete exist because of their disability and need to be addressed continually. On the other hand, sport may be the outlet for channeling energies appropriately.

Further research efforts are now needed in at least two areas. First, the efficacy of specific psychological training programmes such as progressive relaxation, autogenic training, self hypnosis, and biofeedback with wheelchair relaxation, autogenic training, self hyposis, and biofeedback with wheelchair athletes should be initiated. Second, it appears that the somatopyschological relation between physical disability and behaviour is not a direct one, but is mediated by intervening variables. Research is needed to determine the therapeutic value of sport competition, to rehabilitate psychoneutral personality traits as suggested by 
Monnazzi (1982). If the effects of a disability are perceived as present beyond an atypical physique into the psychological areas of life, maybe this negative 'halo' may be removed in total or in part through sport participation.

\section{Résumé}

Lee but de cette etude fut de comparer les characteristiques psychologiques des athletes male et femmelles avec celles des athletes non desavantage.

Les resultas furent etudies enrelation avec l' 'Iceberg Profile' demontre par les athletes elites. Il fut conclu que les athletes males et femmelles en chaise roulant possedent une force mentale et emotionnable superieure a celle de la population en general.

\section{Zusammenfassung}

Der Grund war der Vergleich der psycologischen charaktaere von maenner und Frauen FahrstuhlAthleten und normalen Athleten Zuvergleichen. Das Ergebnis wurde diskutiert in Bedingungen von den 'Iceberg Profile' gezeigt der elite Athleten. Es wurde beschlossen, das Maenner und Frauen Fahrstuhl-Athleten lusitzen vorzuegliche mentalische und emotionelle Gesundheit venn werglichen mit der generalen population.

\section{References}

CRATty BJ 1983 Psychology in contemporary sport (2nd ed.). Prentice-Hall Inc. Englewood Cliffs, NJ

Daniel ML, GoRman D May-June 1983 Don't leave the mind behind. Sports'N Spokes 8-10 Hanin Y 1980 A study of anxiety in sports. In W F Straub Sports Psychology (2nd ed.). Mouvement Ithaca, NY. Publications

HENSCHEN K, EDWARDS S, GORDIN R et al. 1984 Discriminant analysis of psychological profiles comparing male and female NCAA championship gymnasts. Technique 4: 17-19

HENSCHEN K, HORVAT M, FRENCH R 1984 A visual comparison of psychological profiles between able-bodied and wheel chair athletes. Adapted Physical Education Quarterly 1:118-124

KANE JE 1970 Personality and physical abilities. In Contemporary psychology of sport G. S. Kenyon (Ed.) Athletic Institute, Chicago

MCNaIr DM, Lorr M, Droppleman LF 1971 Manual for Profile of Mood States, Education and Industrial Testing Service, San Diego, CA

Monnazzi G 1982 Paraplegics and sports: A psychological survey. International Journal of Sport Psychology 13:85-95

MORGAN WP 1980 Test of champions. Psychology Today 92-108

MORGAN WP, JoHNSON RW 1977 Psychological characterizations of the elite wrestler: A mental health model. Paper presented at the Annual Meeting of the American College of Sports Medicine, at Chicago

MORGaN WP, JoHNSON RW 1978 Personality characteristics of successful and unsuccessful oarsmen. International Journal of Sport Psychology 9:119-133

Morgan WR, Pollock M 1977 Psychologic characterization of the elite distance runner. In Annals of the New York Academy of Sciences, P. Milvy (ed.) 301

Parloff MB, Kelman HC, Frank JD 1954 Comfort, effectiveness and self-awareness as criteria of improvement in psychotherapy. American Journal of Psychiatry 111:343-351

STEADWARD R 1980 Sports and training for the physically disabled. The Australian Journal for Health, Physical Education, and Recreation 91:9-11

Williams J 1980 Personality characteristics of the successful female athlete. In Sports Psychology W. F. Straub (Ed.). Mouvement Publications, Ithaca, NY

Williams LR, PARKIN WA 1980 Personality factor profiles of three hockey groups. International Journal of Sport Psychology 11:113-120 